\title{
Introduction to "How Do Social Networks Influence the Employment Prospects of People with Disabilities?"
}

\author{
Victor G. Devinatz
}

Published online: 21 November 2013

(C) Springer Science+Business Media New York 2013

The Americans with Disabilities Act (ADA), which then President George H.W. Bush signed into law on July 26, 1990 with the Act's amendments in effect since January 1, 2009, disallows, in specific situations, U.S. employers from discriminating against individuals who have disabilities. Although the ADA has extremely broad coverage, in passing the Act, the federal government sought to prevent employment discrimination from occurring against disabled individuals in a manner similar to the role that Title VII of the Civil Rights Act (1964) plays in attempting to eliminate employment discrimination against women and individuals who are members of racial, ethnic and religious minority groups. While disabled individuals have been greatly helped by the ADA over the last 20 years, only $45.6 \%$ of disabled people are employed compared to an employment rate of $83.5 \%$ for nondisabled individuals, as cited in this issue's "Perspectives" Section article. Thus, individuals possessing disabilities are much more likely than their nondisabled counterparts to lack sufficient employment.

In this well-written and well-researched theoretical essay, Christopher R. Langford, a doctoral student in Organization and Management Studies, and Dr. Mark L. Legnich-Hall, Professor of Management, in the Department of Management at the University of Texas at San Antonio, and Dr. Mukta Kulkarni, Associate Professor of Organisational Behaviour and Human Resources Management, at the Indian Institute of Management (Bangalore, India) examine how individuals with disabilities utilize social networks to obtain gainful employment. The authors clearly and succinctly outline the obstacles that disabled individuals confront in network building which results in the underutilization of their networks during the job search process. The authors argue that in order for individuals with disabilities to maximize their chances of obtaining employment, they should develop social networks composed of various contacts who hold "central positions and higher status jobs" in organizations. While developing a number of propositions for guiding the implementation of a future research agenda, the authors also offer a number of practical steps that can be taken by employers, employees and experts working in vocational rehabilitation for improving the employment prospects of disabled individuals.

I welcome employment relations scholars from around the globe to contribute future essays analyzing any employment-related topic from a wide variety of theoretical

V. G. Devinatz $(\square)$

Department of Management \& Quantitative Methods, Illinois State University,

Normal, IL 61790-5580, USA

e-mail: vgdevin@ilstu.edu 
perspectives. Moreover, if any of the journal's readers would like to respond to particular essays or articles published in the "Perspectives" Section, please do not hesitate to contact me with your proposal. I welcome both practitioner-based and scholarly-based articles. I hope that you enjoy this essay and find it most illuminating.

Victor G. Devinatz

Editor of "Perspectives" Section

Department of Management \& Quantitative Methods

Illinois State University

Normal, Illinois 61790-5580 